\title{
Embrittlement Mechanism on Tensile Fracture of 7075 Al Alloy with Friction Stir Process (FSP)
}

\author{
Ming-Hsiang $\mathrm{Ku}^{1}$, Fei-Yi Hung ${ }^{2, *}$, Truan-Sheng Lui ${ }^{1, *}$ and Li-Hui Chen ${ }^{1}$ \\ ${ }^{1}$ Department of Materials Science and Engineering, National Cheng Kung University, Tainan, Taiwan 701, R. O. China \\ ${ }_{2}^{2}$ Institute of Nanotechnology and Microsystems Engineering, Center for Micro/Nano Science and Technology, \\ National Cheng Kung University, Tainan, Taiwan 701, R. O. China
}

7075-T6 Al alloy plates had a friction stir process (FSP) and then performed the natural aging to investigate the effects of various tool rotation speeds $(1230 \mathrm{rpm}, 1450 \mathrm{rpm}, 1670 \mathrm{rpm})$ and natural aging $\left(40^{\circ} \mathrm{C}, 96 \mathrm{~h}\right)$ on the microstructures and tensile fracture properties. The experimental results showed that the grain size became fine equiaxed and the average grain size were 5.2, 5.1, 4.2 $\mu \mathrm{m}$ from low to high tool rotation speeds in the stir zone (SZ). The tensile strength varied with the different rotation speeds of FSP. After natural aging, higher tool rotation speeds had an embrittlement phenomenon on the SZ (detected by nanoindenter) due to the contribution of stirred metal flow and precipitates. Decreasing the tool rotation speeds, the metal flow zones were refined and restrained the brittle behavior to improve the ductility. [doi:10.2320/matertrans.M2010315]

(Received September 13, 2010; Accepted October 14, 2010; Published December 25, 2010)

Keywords: 7075 aluminum alloy, friction stir process (FSP), tensile, nanoindenter

\section{Introduction}

$7 \mathrm{xxx}$ series aluminum alloys are the commercial heat treatment alloys. $7075(\mathrm{Al}-\mathrm{Zn}-\mathrm{Mg}-\mathrm{Cu})$ aluminum alloy are widely used for aerostructures (such as airframe and airfoil) and transportation ${ }^{1-3)}$ due to their good combination of strength, hardness and fracture toughness. At present, 7075 aluminum alloy was mostly assembled by the traditional welding. Notably, friction stir welding (FSW) is a good method to avoid the defects of traditional welding. ${ }^{3)}$

Friction Stir Welding (FSW) is a technology of solid-state joining, because the temperature of welding process had not reached the melting point, there were not many porosities and shrinkage cracks inside materials. Friction Stir Process $(\mathrm{FSP})^{4,5)}$ uses the same methodology as FSW, can produce fine recrystallized grains in the stir zone due to the severe plastic deformation by rotating of the friction tools. However, the characteristics of plastic deformation is closely related to the mechanical properties, its high energy deformation mechanism has still not been examined, and in particular the brittle behavior. ${ }^{6-9)}$

The reports of friction stir welding in 7075 aluminum alloys indicated that the embrittlement phenomenon occurred in the stir zone through FSW and artificial aging $\left(121^{\circ} \mathrm{C}\right.$, $24 \mathrm{~h}){ }^{10)}$ It has been said that the precipitate distribution and precipitate-free zone (PFZ) were the main reason, but that is not strictly true. It must be noted that the relation among precipitated distribution, deformation degree and metal plastic flow zone has not yet been investigated. Notably, the effects of the metal flow and fine equiaxed grains in the SZ how to induce embrittlement behavior of SZ for 7075 aluminum alloy through natural aging is an important role in the applications. In this study of FSP, the density of metal flow zone in the SZ of 7075 aluminum alloy was different under the various tool rotation speed of FSP, and the effects

*Corresponding author, E-mail: fyhung@mail.ncku.edu.tw, z7408020@ email.ncku.edu.tw of natural aging on microstructure and mechanical properties of 7075 aluminum alloy with FSP were investigated to clarify the embrittlement mechanism of tensile fracture on the fine equiaxed microstructure.

\section{Experimental Procedure}

In this study, the $7075 \mathrm{Al}-\mathrm{Zn}$ rolled plates was used. The schematic illustration of the friction stir process (FSP) was showed in Fig. 1 and the tool material was a high-speed steel. The dimension of 7075 specimen was $75 \mathrm{~mm}$ in length, $28 \mathrm{~mm}$ in width and $5 \mathrm{~mm}$ in thickness. The specimens had the solution treatment and T6 treatment to obtain 7075-T6 aluminum alloy as a base metal. The chemical composition of the sample is listed in Table 1. The processing direction of the FSP was parallel to the rolling direction. Three tool rotation speeds were performed including 1230, 1450 and $1670 \mathrm{rpm}$. Tool moving speeds were fixed at $0.58 \mathrm{~mm} \mathrm{~s}^{-1}$ with $1.5^{\circ}$ of tool angle. The downward push force was controlled at 38.7 MPa. The specimen of base metal would be designated as "BM", and those specimens of different rotation speeds would be designated as 1230R, 1450R and 1670R, respectively.

When the temperature of stir zone reached the solution temperature during FSP, the stir zone produced a solution phenomenon and occurred the natural aging. In order to understand the natural aging behavior after FSP, the FSP specimens were put to the oil bath furnace $\left(40^{\circ} \mathrm{C}, 96 \mathrm{~h}\right)$ and investigated the microstructures and mechanical properties at various tool rotation speeds. All microstructures, the grain size and micro-hardness were analyzed. Vickers-Hardness was tested with a load $0.49 \mathrm{~N}$ for $10 \mathrm{~s}$ to understand the relation between the metal flow zones and the microhardness.

In addition, the tensile properties of FSP specimens were performed before (as-welded) and after aging (postweld aging). The direction of tensile specimen was parallel to the rolling direction (friction stir direction) and the location was 


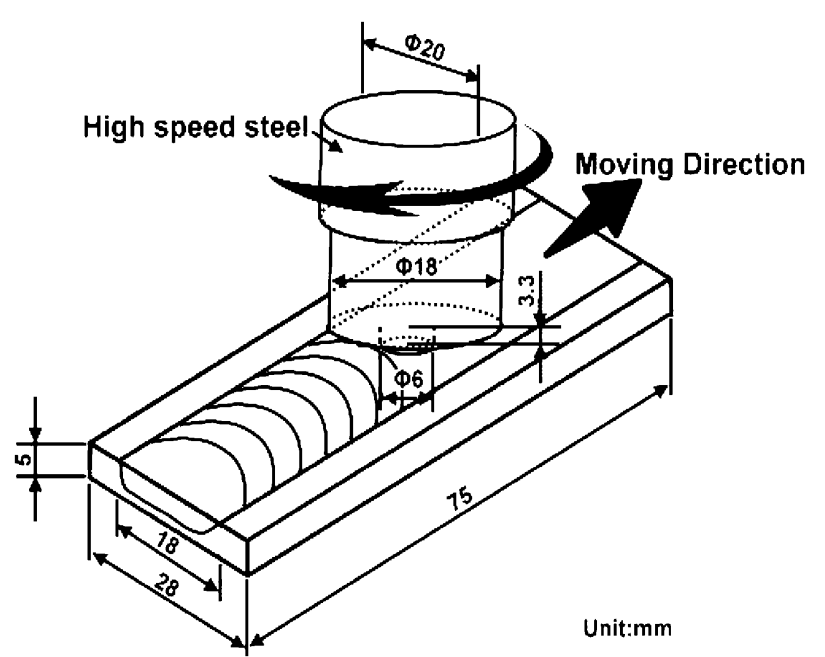

Fig. 1 The schematic illustration of the friction stir process (FSP).

Table 1 Chemical composition of 7075-T6 aluminum alloy (mass\%).

\begin{tabular}{ccccccccc}
\hline Zn & Mg & Cu & Cr & Fe & Ti & Si & Mn & Al \\
\hline 5.67 & 2.44 & 1.71 & 0.26 & 0.16 & 0.02 & 0.05 & 0.01 & Bal. \\
\hline
\end{tabular}

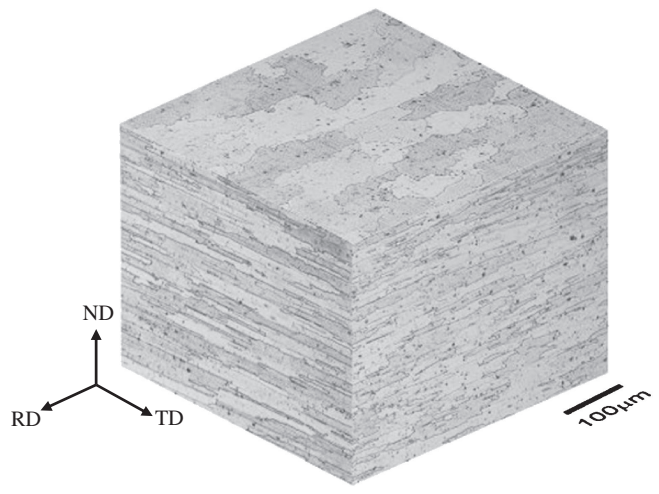

Fig. 2 Optical microstructure of 7075 base metal.

controlled in the stir zone. The strain rate was fixed at $1.67 \times 10^{-3} \mathrm{~s}^{-1}$. The observations of tensile fracture were examined using SEM. Notably, the different deformation degree of SZ always varied with friction stir rotation speed to affect the precipitate distribution and the uniformity of structure. The distribution of elements and the metal flow zones were analyzed by EPMA and nanoindenter to study the tensile embrittlement of FSP specimens.

\section{Results}

The microstructure of BM was a pancake-like structure, as shown in Fig. 2. Figure 3 shows the hardness curves vary with the aging duration for ND (normal direction) plane in the SZ after FSP. Regardless of the tool rotation speeds were high or low, there was an increase tendency in hardness within $48 \mathrm{~h}$. Notably, the hardness value reached HRB 75 as the time increased to $168 \mathrm{~h}$ ( 7 days). In Fig. 4, the microstructure of PD plane in the friction zone were included stir zone (SZ), thermomechanically affected zone (TMAZ) and heat-affected zone (HAZ). SZ has the recrystallization with

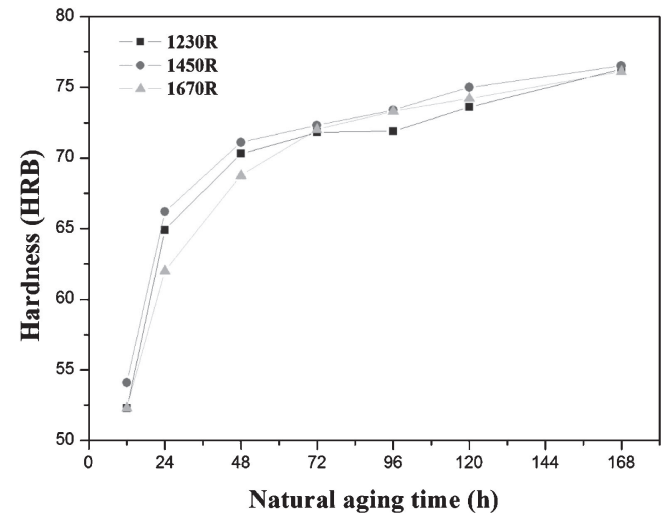

Fig. 3 Hardness curves vary with the aging duration for ND (normal direction) plane in the SZ after FSP.

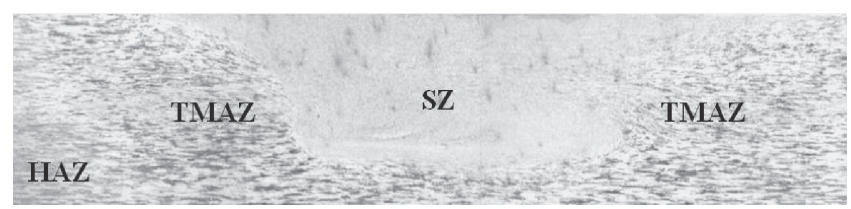

(a)

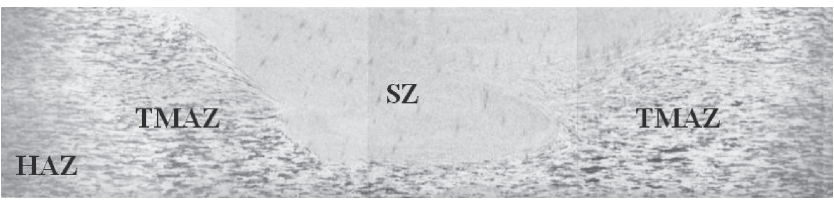

(b)

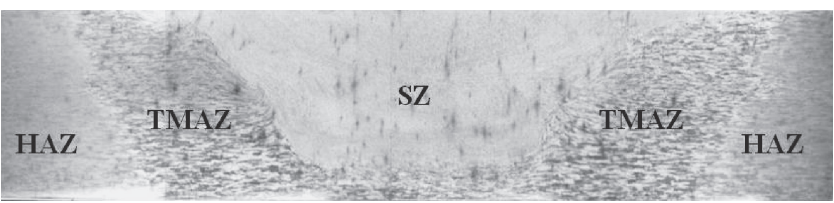

(c)

Fig. 4 Cross-section of PD plane for different tool rotation speeds of friction stir process: (a) 1230R, (b) 1450R, (c) 1670R.

equiaxed grains. TMAZ contains mechanical stir zone and heat affected zone. HAZ was a heat-affected zone far from the stir zone.

In the experiment, advancing side (AS) is defined as the direction of tool rotation with the same direction as processing direction; retreating side (RS) is defined as the direction of tool rotation with the reverse direction of processing direction. In addition, the deformation degree of the SZ varied with the stir rotation speed increasing. Comparing with three tool rotation speeds (1230R, 1450R, 1670R) structures, there was an obvious refinement in the equiaxed grains of SZ, as shown in Fig. 5. The average grain size were 5.2, 5.1, $4.2 \mu \mathrm{m}$ from low to high tool rotation speeds. Figure 6 shows the micro-hardness of PD plane after FSP (the test location was a $1 \mathrm{~mm}$ under the upper surface to avoid the effect of surface traces). The results revealed the hardness of FSP specimens with a natural aging (postweld aging) were higher than as-FSP specimens (un-natural aging, as-welded), but all specimens was still lower than that of BM. Generally speaking, hardness of the as-weld specimens had a tendency to increase with increasing the rotation speeds. The 


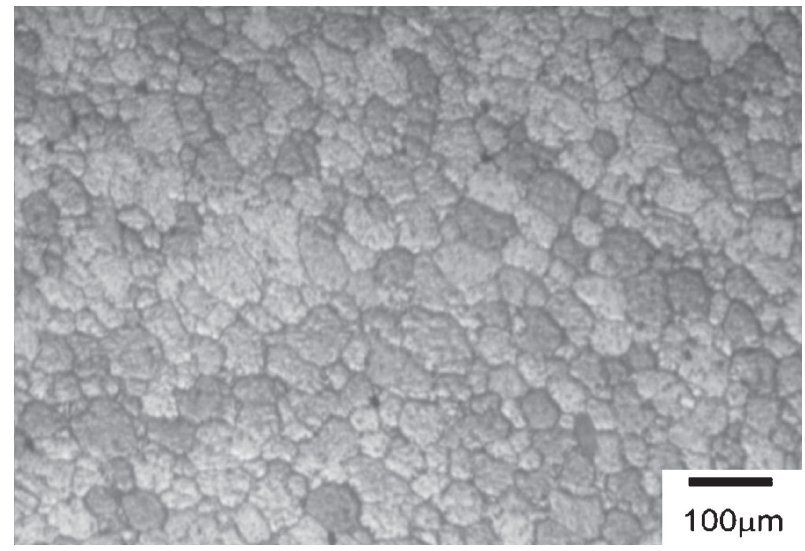

(a)

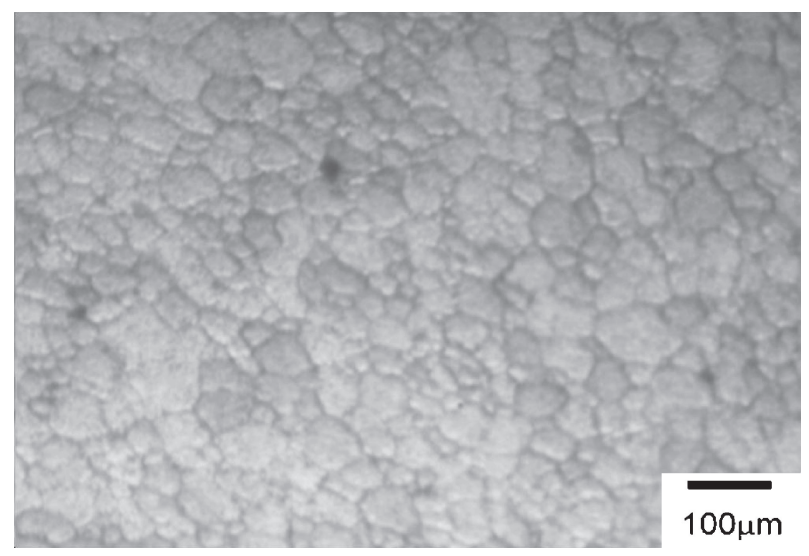

(b)

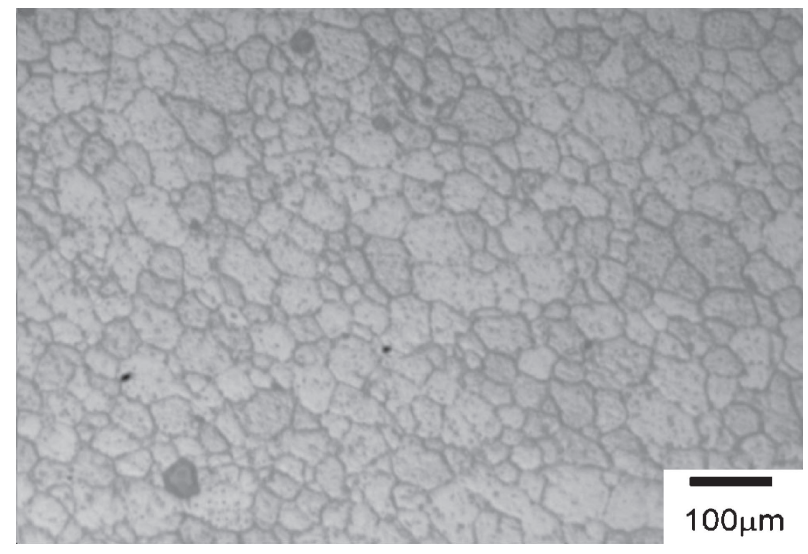

(c)

Fig. 5 Microstructures of SZ for different tool rotation speeds: (a) 1230R, (b) $1450 \mathrm{R}$, (c) $1670 \mathrm{R}$.

main reason is that the higher rotation speeds could fine equiaxed grains to have higher hardness in the matrix. In addition, the hardness of SZ not only was higher than other zones, but also had increase obviously after natural aging.

Figure 7 shows the tensile properties of as-welded specimens and the postweld aging specimens. The result revealed that the YS and UTS of as-welded and postweld aging were lower than those of BM. The 1230R, 1450R and 1670R specimens through postweld aging had different YS and UTS. The YS and UTS of 1230R and 1450R specimens slightly increased, but the YS and UTS of 1670R specimen slightly decreased. According to elongation to estimate the

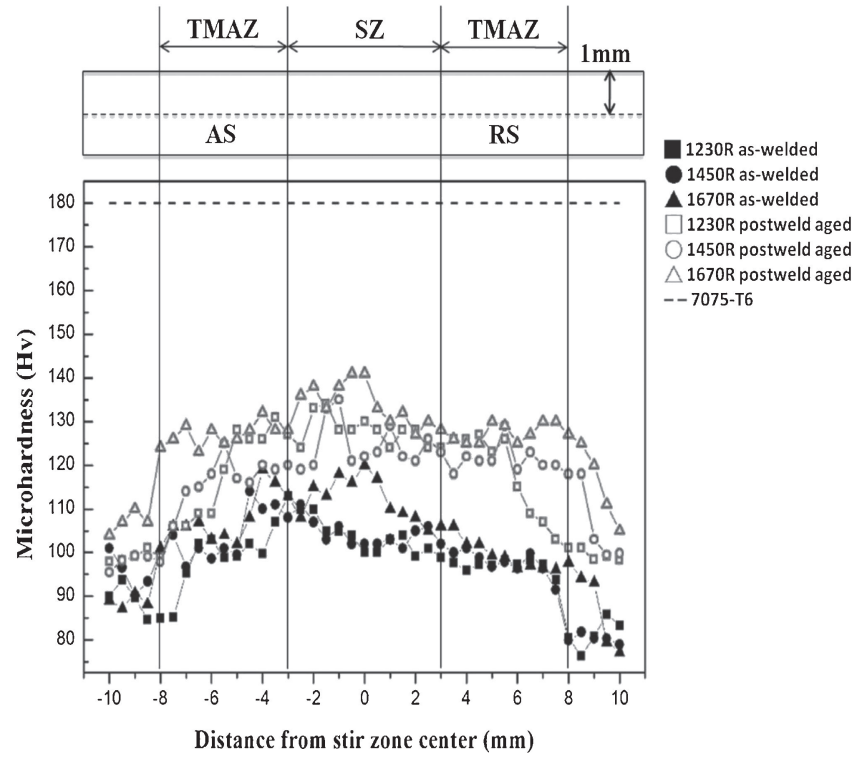

Fig. 6 Micro-hardness of PD plane after FSP. The test location was a $1 \mathrm{~mm}$ under the upper surface. (Un-natural aging: as-welded, with a natural aging: postweld aging)

embrittlement of FSP specimens, it was found that both UE and TE of FSP specimens were lower than those of BM. After natural aging, there was a remarkable increase in the UE and TE of 1230R and 1450R specimens, but those of 1670R specimen deteriorated. In other words, increasing the tool rotation speeds resulted in an embrittlement behavior in the $\mathrm{SZ}$, this even was more obvious after natural aging.

Because of natural aging, the ductility of low tool rotation speed of FSP specimen increases, whereas the high tool rotation speed of FSP specimen induces embrittlement. It can be explained that the different deformation degree certainly has a close relationship with the embrittlement effect induced by natural aging. The tensile fracture surfaces of FSP specimens were observed by SEM. Before and after natural aging, many dimples in the fracture surfaces were observed in Fig. 8 and Fig. 9. Notably, the fracture surface of aswelded specimens had more tear ridges were observed (Fig. 8, dotted circles). After natural aging, the specimens (1230R and 1450R) of tool rotation speeds had more tear ridges and the area fraction of the tear ridges had a tendency to increase from 1230R to 1450R (Fig. 9(a) and (b), dotted circles). However, there were few tear ridges in the $1670 \mathrm{R}$ specimen, as shown in Fig. 9(c).

\section{Discussion}

According to previous reports, ${ }^{11,12)}$ the higher tool rotation speeds, the larger heat-input, which caused both coarse-grain and precipitate growth to affect the mechanical properties in the SZ. Figure 5 shows that the grain size decreases with increasing the tool rotation speed. It can be explained that the inducing heat of present tool rotation speed cannot cause the coarse-grains in the SZ, which confirms the fact that the main mechanism in the SZ was a friction stir deformation characteristics.

From the fracture surface features (Fig. 7 and Fig. 9), the FSP specimens through natural aging were a ductile fracture 


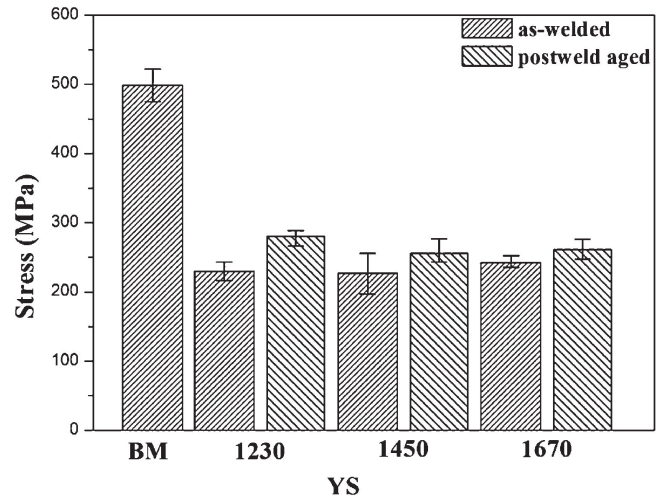

(a)

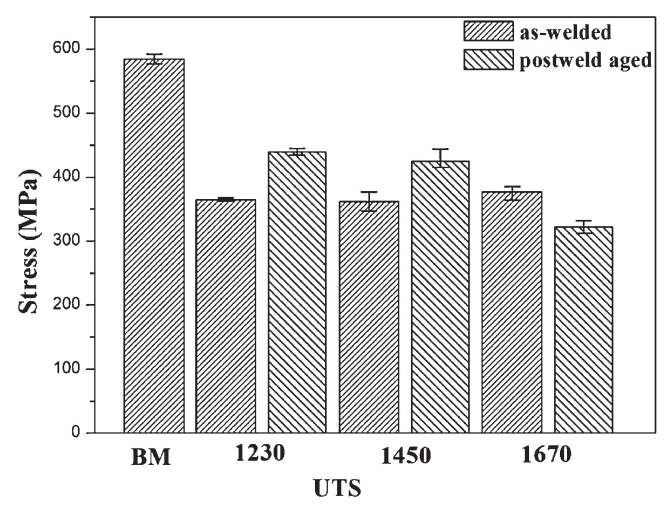

(b)

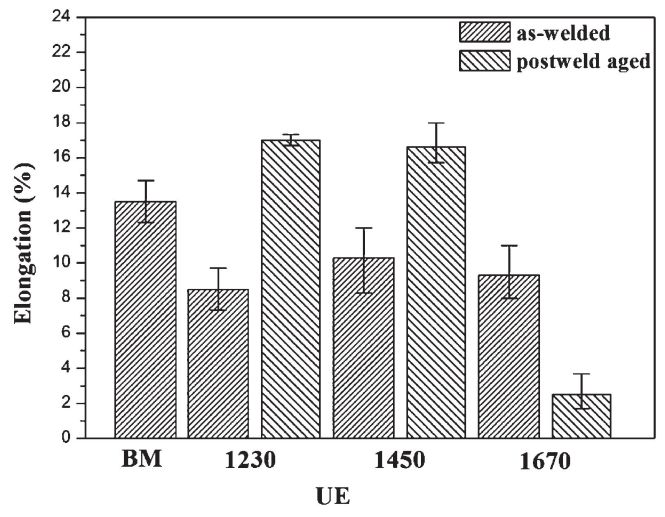

(c)

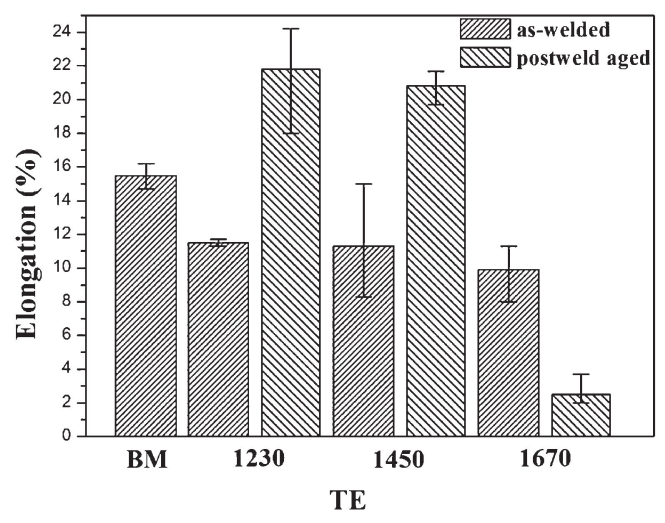

(d)

Fig. 7 Tensile properties of as-welded specimens and postweld aged specimens with different tool rotation speeds: (a) YS, (b) UTS, (c) UE, (d) TE.

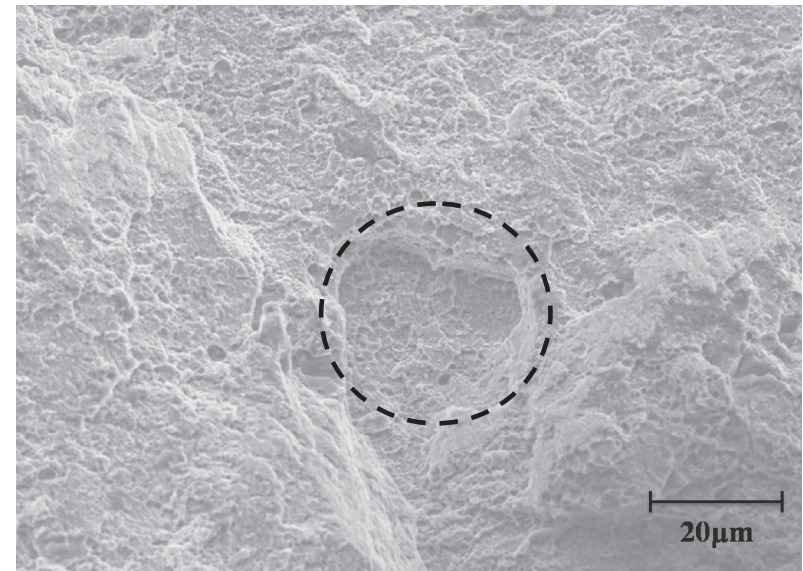

(a)

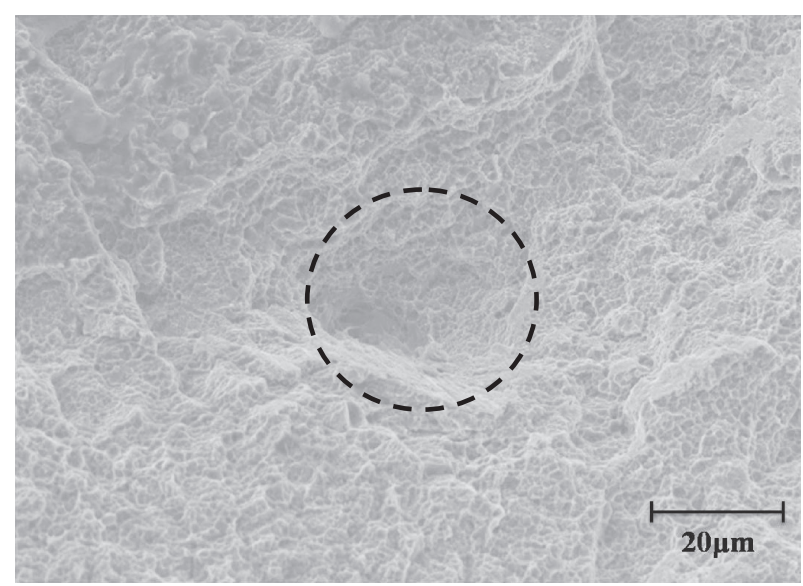

(b)

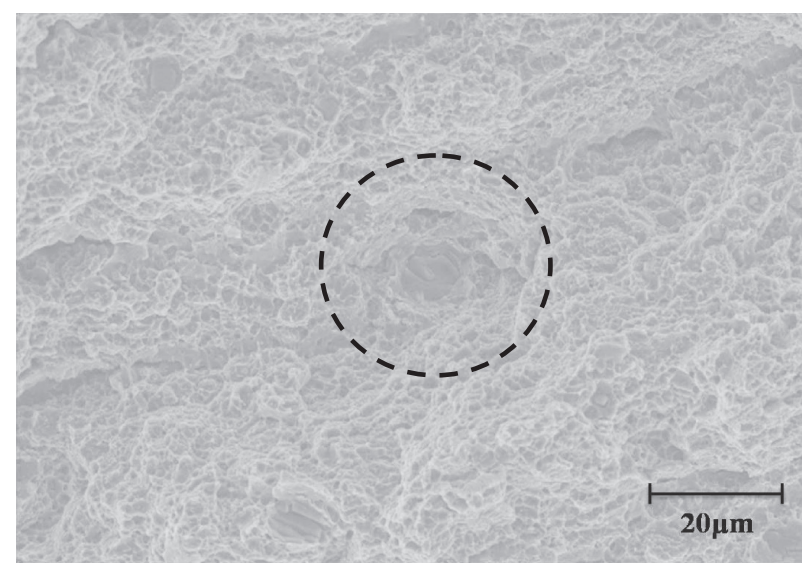

(c)

Fig. 8 Fracture surface of as-welded specimens: (a) 1230R, (b) 1450R, (c) $1670 \mathrm{R}$.

behavior. Notably, the area fraction of tear ridges on the tensile fracture surfaces of higher tool rotation speed specimens through natural aging was relatively fewer. Previous report ${ }^{10)}$ showed the presence of numerous tear ridges on the tensile fracture surface were related the ductility. Corresponding to the tensile fracture surface and elongation, it is clear that the specimen of large area fraction of tear ridges has higher ductility. The main reason is that the matrix would neck to produce micro-voids during tensile testing. As the 


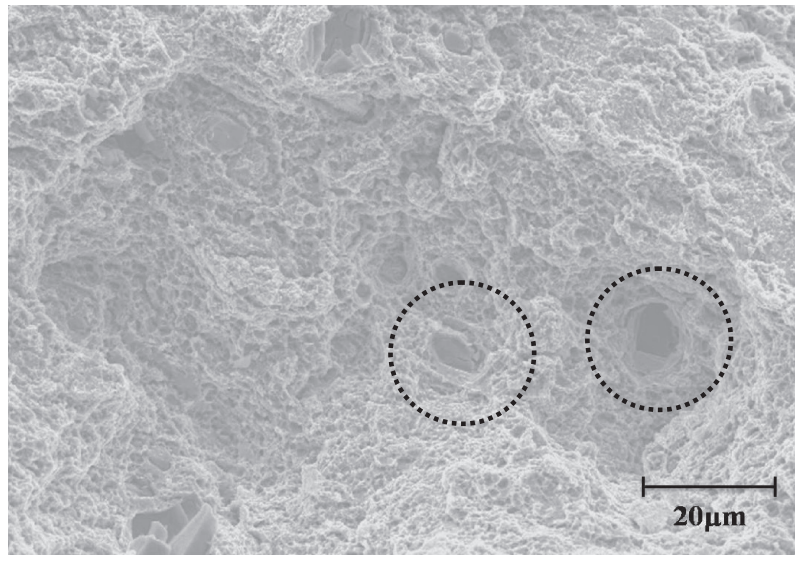

(a)

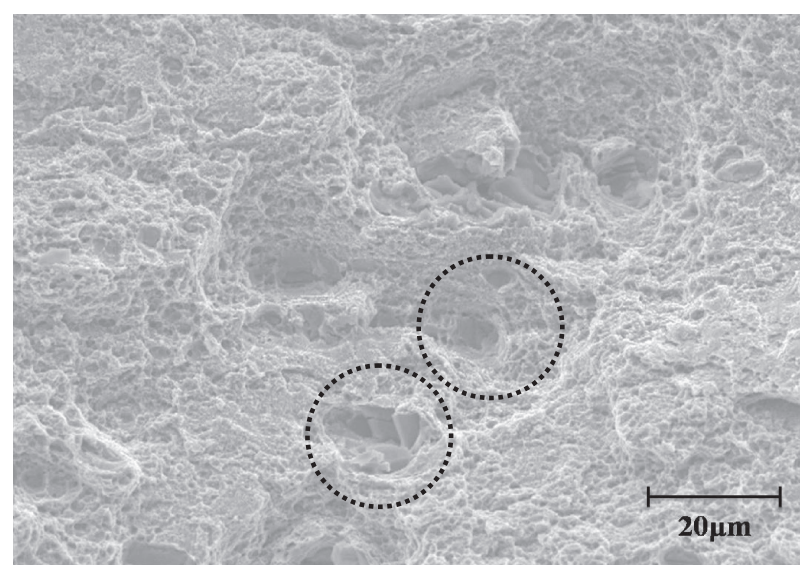

(b)

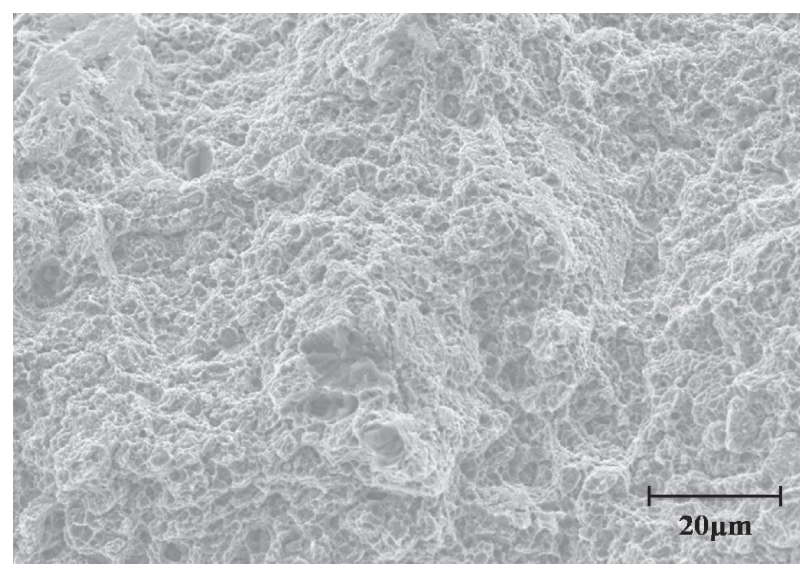

(c)

Fig. 9 Fracture surface of postweld aged specimens: (a) 1230R, (b) 1450R, (c) $1670 \mathrm{R}$.

specimen suffers plastic deformation continually, the microvoid will aggregate because of stress concentration, the tear ridges appeared on fracture surface finally. If the micro-voids did not deform easily to migrate, many dimples would exist on the fracture surface. In fact, the metal flow zone has an effect on the growth and migration of deformation microvoid in the matrix.

When increase the tool rotation speeds, the metal flow zones coarsen, it will cause more metal flow interfaces. The different orientations between the metal flow zones and interface zones restrained the tensile micro-voids to migrate and lead to the embrittlement. For high tool rotation speed conditions, the natural aging certainly affected the embrittlement mechanism (low deformation degree was not obvious) from the data of 1670R specimen before aging (as-welded) and after aging (postweld aging). In other words, both the density of metal flow zone (1st step) and the distribution of precipitate for natural aging (2nd step) induced to the embrittlement mechanism of the SZ.

In fact, a higher tool rotation speed had a larger plastic deformation degree. If added the distribution of precipitated, the brittle fracture behavior occurred. So, the specimens of postweld aging were analyzed using EPMA to clarify the relationship between the plastic deformation degree of FSP and the distribution of element. Figure 10 shows that the elements $(\mathrm{Zn}, \mathrm{Mg}$ and $\mathrm{Cu})$ of $1230 \mathrm{R}$ and 1450R specimens were uniformly distributed, but the elements of 1670R specimen were concentrated in the metal flow zones. The EPMA data demonstrates that the specimen of high tool rotation speed not only has obvious the metal flow zones (high density and coarse metal band) but also results in nonuniform of in the distribution of elements. We have good grounds for thinking that the natural aging of the metal flow zones will induce the different mechanism of precipitated hardness.

Judging from the above, in order to understand the relationship between hardness of the metal flow zones and the distribution of elements, the hardness of metal flow zones and the area around were measured using a nanoindenter (Fig. 11). Figure 11(a) shows the 1670R specimen has coarse metal flow zones and many metal band interfaces. According to nano-indention data (Fig. 11(b)), the hardness of the metal flow zones was higher than that of the non metal flow zones in the SZ after natural aging. It is obvious that the deformation resistance of coarse metal flow zones was different from the other zones. So, the present stirring zones had the critical speed to form coarse metal flow zones. Due to the coarse metal flow zones and the precipitated hardness, the high tool rotation speed of FSP specimen had the embrittlement. These are the reasons why the elongation of 1670R specimens had decreased from $\sim 10 \%$ to $3 \%$ (Fig. 7) after natural aging. From tensile fracture point of view, the precipitate strengthening was obvious and the deformation resistance of metal flow zones was different from that of the matrix (non-metal flow zones) resulting in more tear ridges in the fracture surface (Fig. 9). Therefore, both the interfaces bands of the metal flow have the stress concentration and non-uniform precipitated that cause the embrilltement effect.

\section{Conclusion}

After FSP, 7075-T6 Al alloy had fine equiaxed structure and the average grain size decreased with increasing the tool rotation speeds in the stir zone. Higher tool rotation speeds, which caused the coarse metal flow zones to affect the mechanical properties. The metal flow zones had higher deformation resistance and non-uniform precipitated hardness that resulted in the embrittlement in high tool rotation speed of FSP specimens. 


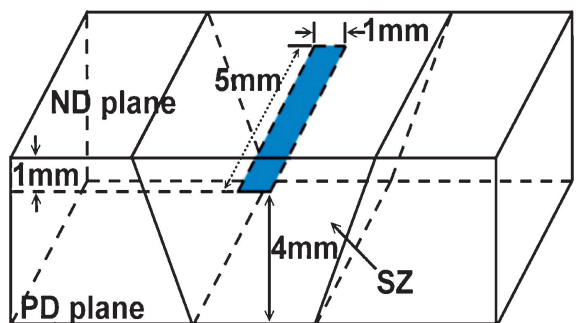

(a)

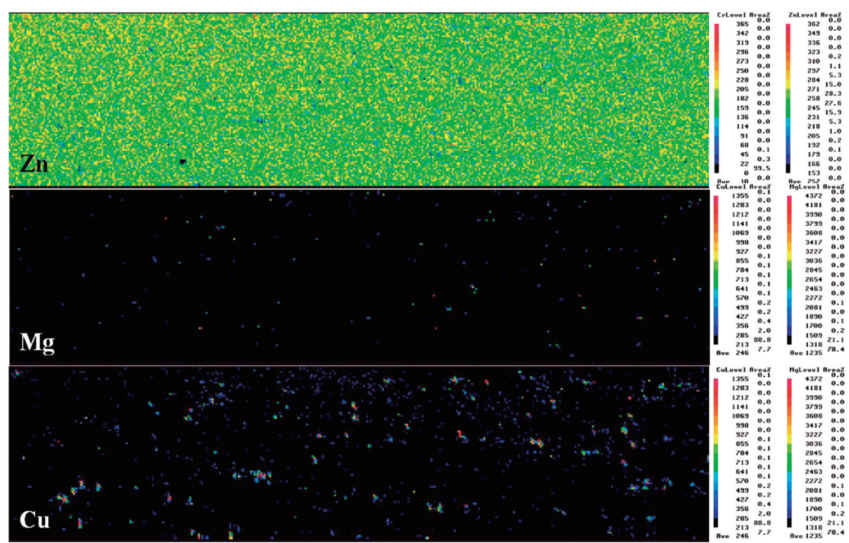

(b)
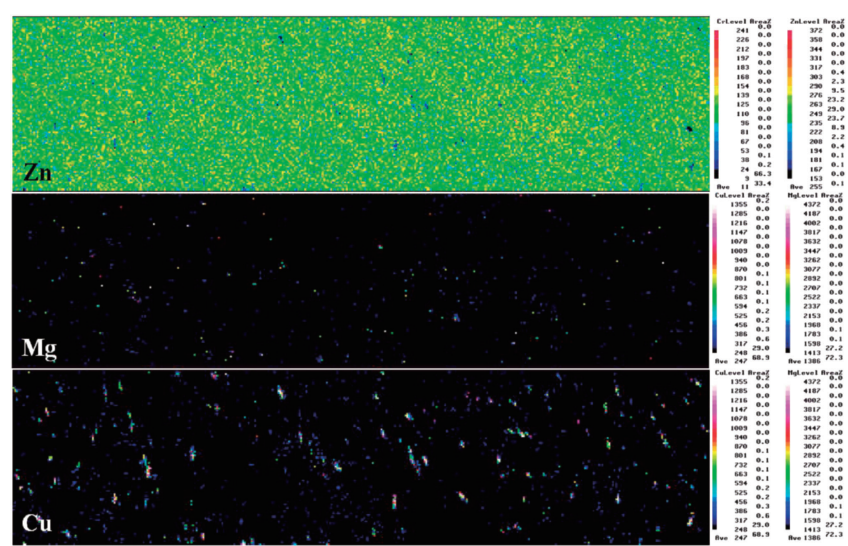

(c)

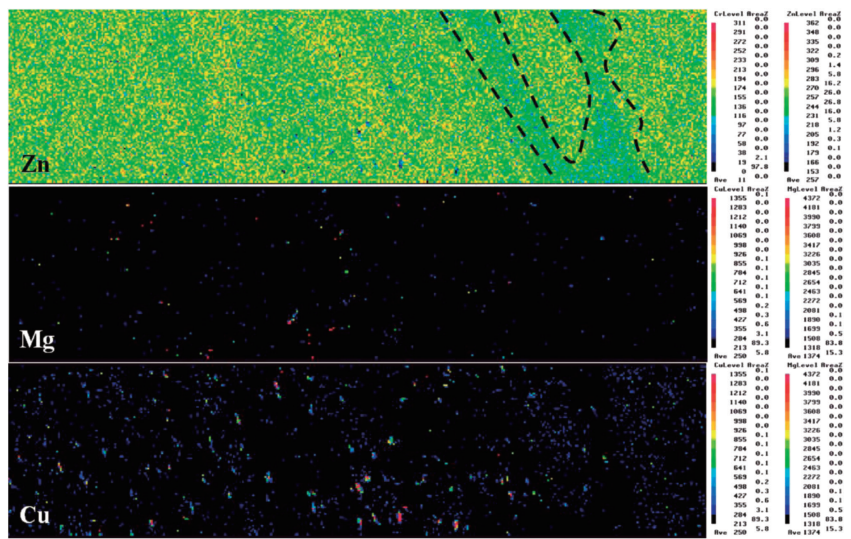

(d)

Fig. 10 EPMA of the postweld aged specimens with different tool rotation speeds: (a) the location of sample, (b) 1230R, (c) 1450R, (d) 1670R.

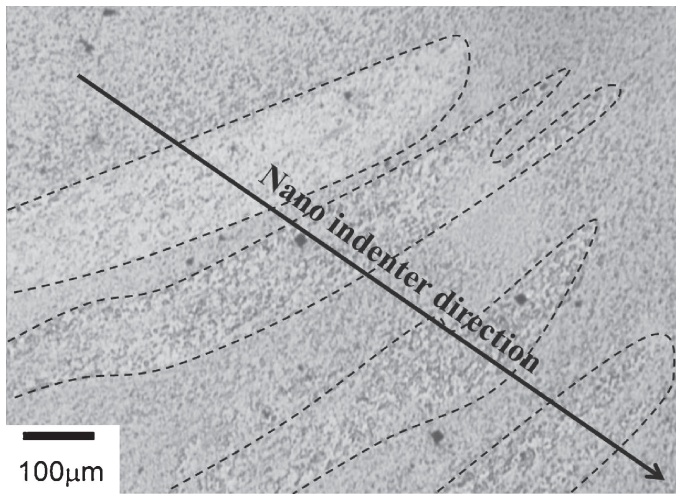

(a)

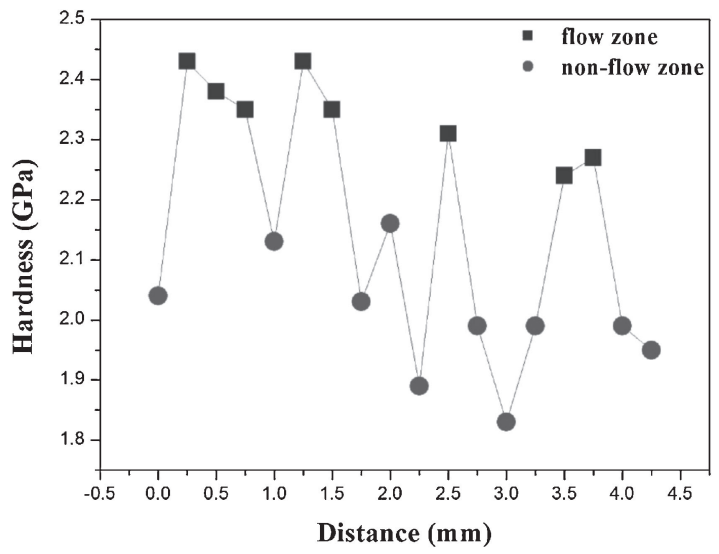

(b)

Fig. 11 (a) SZ structure of 1670R specimen, (b) nano indentation hardness of metal flow zones and the area around.

\section{Acknowledgements}

The authors are grateful to National Cheng Kung University, the Center for Micro/Nano Science and Technology (D98-2700) and NSC 99-2622-E-006-132 for the financial support.

\section{REFERENCES}

1) B. Smith: Adv. Mater. Process. 161 (2003) 41-44.

2) B. Kumar, C. Widener, A. Jahn, B. Tweedy, D. Cope and R. Lee: 46th Structural Dynamics \& Materials Conference, (2005) p. 1.

3) W. M. Thomas and E. D. Nicholas: Mater. Des. 18 (1997) 269-273.

4) Z. Y. Ma, R. S. Mishra and M. W. Mahoney: Acta Mater. 50 (2002) 4419-4430.

5) R. S. Mishra, M. W. Mahoney, S. X. McFadden, N. A. Mara and A. K. Mukherjee: Scr. Mater. 42 (2000) 163-168.

6) F. J. Humpheys and M. Hathrly: Recrystallization and Related Annealing Phenomena, (Pergamon, Oxford, UK, 1996) pp. 363-392.

7) K. V. Jata and S. L. Semiatin: Scr. Mater. 43 (2000) 743-749.

8) J. Q. Su, T. W. Nelson, R. Mishra and M. Mahoney: Acta Mater. 51 (2003) 713-729.

9) C. G. Rhodes, M. W. Mahoney, M. H. Bingel and M. Calabrese: Scr. Mater. 48 (2003) 1451-1455.

10) M. W. Mahoney, C. G. Rhodes, J. G. Flintoff, R. A. Spurling and W. H. Bingel: Metall. Mater. Trans. A 29A (1998) 1955-1964.

11) O. Frigaard, O. Grong and O. T. Midling: 7th INALCO International Conference, (1998) pp. 197-207.

12) Y. G. Kima, H. Fujii and T. Tsumura: Mater. Sci. Eng. A 415 (2006) 250-254. 